\title{
Percutaneous coronary intervention of a tortuous and complex circumflex lesion using the robotic CorPath GRX system
}

\author{
Aleksander Zelias', Arif A Khokharr2, ${ }^{3}$, Klaudia Proniewska ${ }^{3}$, Adriana Zlahoda-Huzior ${ }^{4}$, Rossella Ruggiero², Kailash \\ Chandra ${ }^{2}$, Francesco Giannini², Dariusz Dudek ${ }^{5}$
}

${ }^{1}$ Center for Invasive Cardiology, Electrotherapy and Angiology in Nowy Sacz, Nowy Sącz, Poland ${ }^{2}$ Interventional Cardiology Unit, GVM Care and Research, Maria Cecilia Hospital, Cotignola, Italy ${ }^{3}$ Department of Bioinformatics and Telemedicine, Jagiellonian University Medical College, Kraków, Poland ${ }^{4}$ Department of Measurement and Electronics, AGH University of Science and Technology, Kraków, Poland IInstitute of Cardiology, Jagiellonian University Medical College, Kraków, Poland

Correspondence to:
Aleksander Zelias, MD,
Center for Invasive
Cardiology,
Electrotherapy and
Angiology,
Kilińskiego 68,
33-300 Nowy Sącz, Poland,
phone: +48 18 540 0200.
e-mail:
aa.zelias@gmail.com
Copyright by the Author(s),
2021
Kardiol Pol. 2021;
79 (9): 1044-1045;
DOI: 10.33963/KP.a2021.0057
Received:
April 22, 2021
Revision accepted:
July 5, 2021
Published online:
July 6, 2021

Robotic-assisted percutaneous coronary interventions (R-PCI) dramatically reduce physician radiation exposure and potential musculoskeletal injuries [1]. In addition, accumulating evidence has demonstrated $\mathrm{R}-\mathrm{PCl}$ safety and efficacy in a broad range of lesion types [2, 3].

We report the first case of R-PCl performed in Poland using the CorPath GRX (Corindus Vascular Robotics) system (Supplementary material, Figures $S 1$ and S2) to treat a complex tortuous lesion of the left circumflex (CX) artery.

A 47-year-old male with previous $\mathrm{PCI}$ to the left anterior descending artery (LAD) was referred with worsening typical angina (Canadian Cardiovascular Society class III). Echocardiography revealed hypokinesia in the basal and mid-segments of the inferior and posterior wall. Diagnostic angiography revealed a short left main stem (LMS) and a tortuous circumflex (CX) artery with a critical lesion in the mid-vessel (Figure 1A) associated with a separate critical lesion in the $1^{\text {st }}$ obtuse marginal (OM) branch (Figure 1B). The right coronary artery was hypoplastic and the LAD stent was patent with no significant other lesions. A provisional strategy was planned to treat the disease in the $C x / O M 1$.

Six Fr right radial access was secured and the operator manually cannulated the LMS with a $6 \mathrm{Fr}$ AL1 guiding catheter. Following successful and stable cannulation, the guiding catheter was connected to the robotic arm, and the rest of the procedure was completed from the remote workstation (Supplementary material, Figure S3). A Runthrough NS Floppy wire (Terumo systems, Somerset, NJ, USA) was selected and robotically advanced to the distal vessel, with the tortuosity and diseased segment successfully navigated using a combination of manual joystick controls and pre-set automation techniques (Figure 1C). A $2.5 \times 27 \mathrm{~mm}$ non-compliant (NC) balloon was used to pre-dilate the lesion. Precise measurement (1 $\mathrm{mm}$ precision) of the lesion length was performed using the robotic system and accordingly a $3.0 \times 38 \mathrm{~mm}$ drug-eluting stent (Promus PREMIER, Boston Scientific, Marlborough, MA, USA) was advanced and successfully implanted at the intended site (Figure 1D). Post-dilatation of the proximal portion of the stent was performed with a $3.5 \times 15 \mathrm{~mm} \mathrm{NC}$ balloon. Following main vessel stenting, the main vessel wire was retracted and robotically advanced into the OM1 branch which was treated with balloon-only angioplasty using a $2.0 \times 12 \mathrm{~mm} \mathrm{NC}$ inflated at 10 atm (Figure 1E).

Final angiography revealed a good angiographic result, optimal stent expansion with no complications (Figure 1F). Fluoroscopy time was 22 minutes, radiation dose was $943 \mathrm{mGy}$ and total contrast volume was $150 \mathrm{ml}$.

This case demonstrates how the R-PCI system can be used to safely and successfully treat complex lesions. Despite the lack of haptic feedback, wiring of this tortuous vessel was achieved using the joystick controls manually aided by the built-in automated robotic movements. The CorPath GRX system can accommodate multiple coronary wires and devices simultaneously. In such instances, one wire and one device are allocated to the active 

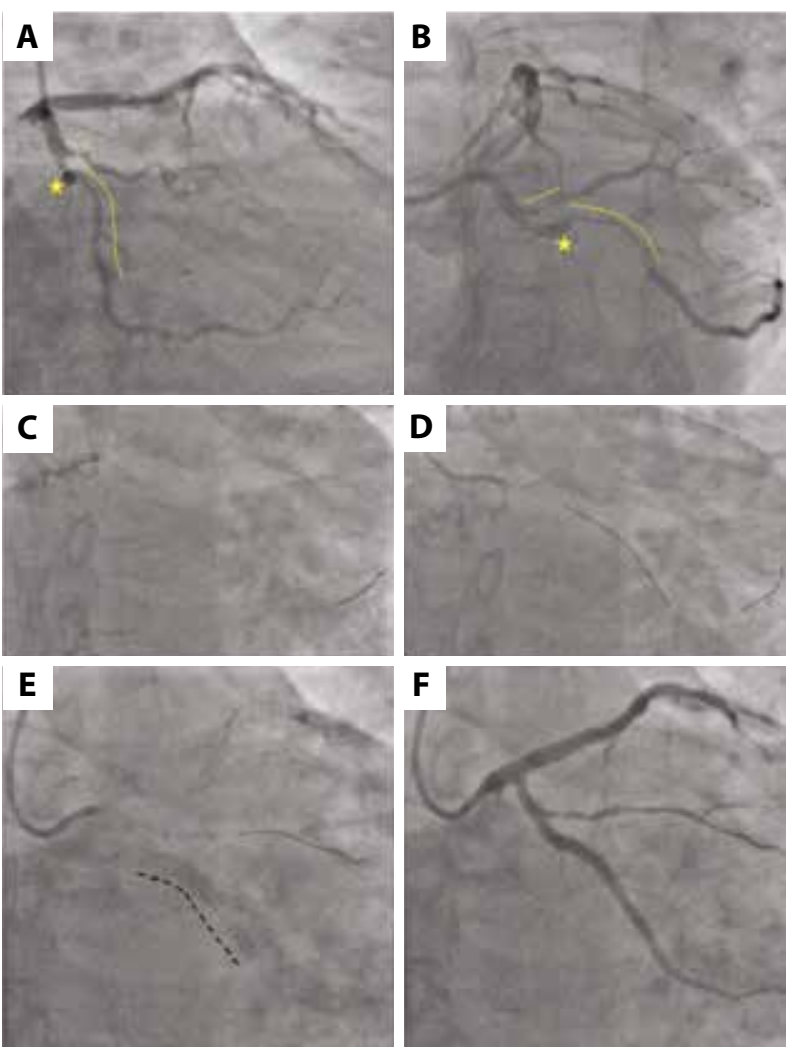

Figure 1. Robotic-assisted percutaneous coronary interventions ( $\mathrm{R}-\mathrm{PCl}$ ) of the tortuous complex circumflex lesion. Baseline angiography $(\mathbf{A}-\mathbf{B})$ demonstrates the critical lesions (yellow dotted lines) in the mid circumflex artery and proximal segment of the $1^{\text {st }}$ marginal branch. The tortuous segment of the vessel (yellow star) arises just before the critical lesion in the mid-vessel. Through a $6 \mathrm{Fr}$ amplatz left guiding catheter a 0.014 " coronary wire was advanced distally (C) using the robotic controls and following pre-dilatation, the stent was advanced and deployed (D-E) in the intended position (dashed black line). The marginal lesion was wired and treated with balloon angioplasty (E) using the robotic controls. The final result (F) was optimal without any angiographic complications

drive and can be controlled from the console, whilst the remaining wires and devices cannot be maneuvered but remained fixed in the passive drive. This can enable operators to treat complex lesions including bifurcations and perform final kissing inflations when required. The presence of a short LMS required repeated repositioning and stabilization maneuvers of the guiding catheter, which were all performed using the guide catheter joystick control. During initial wiring, the guide catheter disengaged into the aorta with subsequent loss of wire position. With the robotic controls, the guide catheter was safely manipulated back into a more stable position achieving semi-selective cannulation of the $\mathrm{Cx}$ artery.

Worldwide experience with $\mathrm{R}-\mathrm{PCl}$ systems is growing, enabling increasingly complex coronary lesions to be treated safely and effectively, without compromising procedural time, and with improved operator safety $[4,5]$. In our case, the primary operator completed the entire procedure without wearing any radioprotection sat at the robotic console, which was located within the operating room.

\section{Supplementary material}

Supplementary material is available at https://journals. viamedica.pl/kardiologia_polska.

\section{Article information}

Conflict of interest: None declared.

Open access: This article is available in open access under Creative Common Attribution-Non-Commercial-No Derivatives 4.0 International (CC BY-NC-ND 4.0) license, allowing to download articles and share them with others as long as they credit the authors and the publisher, but without permission to change them in any way or use them commercially. For commercial use, please contact the journal office at kardiologiapolska@ptkardio.pl.

How to cite: Zelias A, Khokhar AA, Proniewska K, et al. A Percutaneous coronary intervention of a tortuous and complex circumflex lesion using the robotic CorPath GRX system. Kardiol Pol. 2021; 79(9): 1044-1045, doi: 10.33963/KP.a2021.0057.

\section{REFERENCES}

1. Maor E, Eleid MF, Gulati R, et al. Current and future use of robotic devices to perform percutaneous coronary interventions: a review. J Am Heart Assoc. 2017; 6(7): e006239, doi: 10.1161/JAHA.117.006239, indexed in Pubmed: 28739860.

2. Weisz G, Metzger DC, Caputo RP, et al. Safety and feasibility of robotic percutaneous coronary intervention: PRECISE (Percutaneous Robotically-Enhanced Coronary Intervention) Study. J Am Coll Cardiol. 2013;61(15): 1596-1600, doi: 10.1016/j.jacc.2012.12.045, indexed in Pubmed: 23500318.

3. Caputo $R$, Lesser $A$, Fischi $M$, et al. Safety and feasibility of robotic $\mathrm{PCl}$ utilizing radial arterial access. J Am Coll Cardiol. 2015; 65(10): A203, doi: 10.1016/s0735-1097(15)60203-0.

4. Kapur V, Smilowitz NR, Weisz G. Complex robotic-enhanced percutaneous coronary intervention. Catheter Cardiovasc Interv. 2014; 83(6): 915-921, doi: 10.1002/ccd.25271, indexed in Pubmed: 24167108.

5. Naghi J, Harrison J, Ang L, et al. Robotic versus manual percutaneous coronary intervention: effect on procedure time for simple and complex lesions. J Am Coll Cardiol. 2016; 67(13): 229, doi: 10.1016/s07351097(16)30230-3. 